\title{
Distúrbio de voz como doença relacionada ao trabalho no Brasil: reconhecimento e desafios
}

\author{
Voice disorder as a work-related disease in Brazil: \\ recognition and challenges
}

\section{Problemas de voz como enfermedad relacionada con el trabajo en Brasil: reconocimiento y desafío}

Adriane Mesquita de Medeiros 1
Marcel de Toledo Vieira 2

doi: 10.1590/0102-311X00174219
Agradecemos pela apreciação do nosso artigo Ausência ao Trabalho por Distúrbio Vocal de Professores da Educação Básica no Brasil 1. O comentário reforça a necessidade de maior enfrentamento para a redução dos distúrbios vocais, e consequente absenteísmo, por meio da adoção de medidas que possam ser praticadas no âmbito da saúde ocupacional.

Apesar das evidências científicas confirmarem a relação entre os fatores de risco ocupacionais e o distúrbio vocal, verificamos que as legislações e políticas públicas específicas de incentivo à promoção da saúde vocal de professores têm sido predominantemente direcionadas para capacitações educativas sobre os cuidados com a voz. São escassas as intervenções nos aspectos contextuais do trabalho, como identificação e redução/eliminação dos riscos existentes à saúde vocal no ambiente e organização do trabalho, os treinamentos de aquecimento, desaquecimento e expressividade vocal, assim como as avaliações médicas e fonoaudiológicas periódicas para a identificação precoce do distúrbio vocal.

Após longo período de busca pelo reconhecimento do distúrbio de voz como doença relacionada ao trabalho (DVRT), o protocolo do DVRT foi oficialmente publicado pelo Ministério da Saúde 2. Esse distúrbio é definido no documento como qualquer forma de disfonia diretamente relacionada ao uso da voz durante a atividade profissional que diminua, comprometa ou impeça a atuação e/ou comunicação do trabalhador, podendo ou não haver lesão histológica nas pregas vocais secundárias ao uso da voz (CID-10 J-38, R-49).

O reconhecimento da relação entre trabalho e voz é mais difícil diante do caráter etiológico multifatorial do distúrbio vocal. Alguns desafios estão postos: Como mensurar a influência da gestão escolar e das especificidades do trabalho docente na identificação do distúrbio vocal e nas demais comorbidades associadas? Como lidar com as distintas manifestações dos sintomas vocais e de restrições no uso da voz quando nenhuma lesão laríngea evidente é encontrada? Como proceder para diferenciar o estágio inicial/funcional de um distúrbio vocal ou uma simulação, principalmente no setor público? É possível admitir um professor para o exercício da docência com a presença de alteração laríngea, porém sem queixa de sintomas vocais? Como manejar os casos de distúrbio vocal e sua tendência de cronicidade, com repercussões sobre a capacidade para o trabalho? Como manter a capacidade de trabalho dos professores que não percebem ou não valorizam os sintomas e sinais vocais? Espera-se que a melhoria da legislação previdenciária favoreça o reconhecimento do nexo causal e amplie os direitos trabalhistas aos professores, além de contribuir para o aumento de subsídios para as ações de
1 Universidade Federal de Minas Gerais, Belo Horizonte, Brasil.

2 Universidade Federal de Juiz de Fora, Juiz de Fora, Brasil.

Correspondência A. M. Medeiros

Universidade Federal de Minas Gerais.

Av. Prof. Alfredo Balena 190, Belo Horizonte, MG 30130-100, Brasil. adrianemmedeiros@hotmail. com 
vigilância em saúde. Com a inclusão do DVRT na lista de notificação compulsória no Brasil, o problema da subnotificação precisa ser superado.

Concordamos com a recomendação de se investigar a recorrência anual do absenteísmo por distúrbio vocal entre os professores e os custos anuais ao país. Um estudo realizado nos Estados Unidos investigou o custo do absenteísmo por problema de voz considerando o salário perdido e a diminuição da produtividade do trabalho. Apesar do enorme impacto econômico observado, estimado em um milhão de dólares por ano, os autores ressaltam que o custo real provavelmente seria maior se outros fatores como despesa com professores substitutos e impactos em atividades não relacionadas ao trabalho fossem considerados 3 . Os autores mencionam que o presenteísmo gera custos ainda maiores e também tem sido preocupante nas escolas, pois os professores permanecem no exercício da docência mesmo sem condições vocais para cumprir suas tarefas 3,4. Na medida em que os professores continuam usando a voz sem descanso, os distúrbios vocais tornam-se mais frequentes e crônicos 4 .

Estudos longitudinais de caráter nacional e ampliações das ações voltadas para a saúde do trabalhador requerem maior investimento, porém, há dificuldades em se avançar diante dos cortes orçamentários no país. A valorização do professor perpassa pela melhoria das adequações do ambiente e da organização escolar, e as evidências científicas servem de suporte para a tomada de decisões na priorização das intervenções.

\section{Colaboradores}

A. M. Medeiros e M. T. Vieira participaram da redação e aprovação final da réplica.

\section{Informações adicionais}

ORCID: Adriane Mesquita de Medeiros (00000002-2817-2555); Marcel de Toledo Vieira (00000002-0456-380X).

\section{Referências}

1. Medeiros AM, Vieira MT. Ausência ao trabalho por distúrbio vocal de professores da Educação Básica no Brasil. Cad Saúde Pública 2019; 35 Suppl 1:e00171717.

2. Masson MLV, Ferrite S, Pereira LMA, Ferreira LP, Araujo TM. Em busca do reconhecimento do distúrbio de voz como doença relacionada ao trabalho: movimento histórico-político. Ciênc Saúde Colet 2019; 24:805-16.

3. Rosow DE, Szczupak M, Saint-Victor S, Gerhard JD, DuPont C, Lo K. The economic impact of vocal attrition in public school teachers in Miami-Dade County. Laryngoscope 2016; 126:665-71.

4. Lee Y-R, Kim H-R, Lee S. Effect of teacher's working conditions on voice disorder in Korea: a nationwide survey. Ann Occup Environ Med 2018; 30:43.

Recebido em 08/Set/2019

Aprovado em 16/Set/2019 